\title{
LA COLECCIÓN DE CROMOS EL EMBLEMA DE LAS FLORES (BARCELONA, C. 1910): LA DIFUSIÓN DEL SIMBOLISMO FLORAL DE LATINOAMÉRICA A EUROPA
}

\author{
THE COLLECTION OF ILLUSTRATED CARDS THE EMBLEM \\ OF FLOWERS (BARCELONA, C. 1910): THE DISSEMINATION \\ OF FLORAL SYMBOLISM FROM LATIN AMERICA TO EUROPE
}

\author{
FÁTIMA LÓPEZ PÉREZ*
}

RESUMEN: El presente artículo es el resultado de una investigación interdisciplinaria e internacional sobre la colección de cromos El emblema de las flores (c.1910), publicada en Barcelona y de estilo Art Nouveau. El objeto de estudio se analiza a nivel formal, iconográfico y estilístico, fusionando diversas áreas interdisciplinarias: historia, arte, literatura, botánica y sociología. Se plantean relaciones entre Latinoamérica y Europa sobre el lenguaje simbólico de las flores, ya que los cromos se basaron en el contenido de un libro publicado en Venezuela y de gran repercusión en países americanos y europeos. Nuestro objetivo es contribuir al conocimiento sobre la relación entre el lenguaje floral y los cromos antiguos, dos temas que han pasado desapercibidos para la investigación histórico-artística. Consideramos importante poner de manifiesto su relevancia como testimonio literario y artístico que refleja los intereses comunes entre Latinoamérica y Europa durante los siglos XIX y XX. Las conclusiones permiten afirmar la modernidad y excepcionalidad de esta obra de arte gráfico que definimos como la mejor colección española sobre el lenguaje de las flores.

Palabras Clave: Lenguaje de las flores, cromos antiguos, mujer-flor, siglos XIX-XX, Art Nouveau.

AвSTRACT: This article is the results of interdisciplinary and international research, an unpublished study on the collection of illustrated cards The Emblem of Flowers (c.1910), published in Barcelona in the Art Nouveau style. The object of study is to analyse them at a formal, iconographic and stylistic level, merging various interdisciplinary area, such as, history, art, literature, botany and sociology. Relations are proposed between Latin America and Europe on the symbolic language of flowers since the cards were

\footnotetext{
${ }^{\star}$ Los resultados de la investigación que presentamos se integran en el proyecto Entre ciudades: el arte y sus reversos en el período de entre siglos (XIX-XX) del GRACMON (Grupo de investigación en Historia del Arte y del Diseño Contemporáneos), Departamento de Historia del Arte, Universidad de Barcelona, España. Investigadoras Principales Dra. Teresa-M. Sala y Dra. Irene Gras. Ministerio de Economía, Industria y Competitividad del Gobierno de España PID2019-105288GB-I00, 2020-2023.

** Doctora en Historia del Arte. Profesora del Departamento de Historia del Arte e investigadora del grupo GRACMON, Universidad de Barcelona, Barcelona, España. Correo electrónico: fatimalopez@ub.edu. Orcid: http://orcid.org/0000-0002-4190-8109.
} 
based on the content of a book published in Venezuela, which had a great impact in American countries. Our aim is to contribute to the knowledge about the relationship floral language and antique card collections. Two topics that have not been noticed by historical-artistic researchers. It is important to highlight their relevance as a literary and artistic testimony that reflects the common interests shared by Latin America and Europe during the 19th and 20th centuries. The conclusions allow us to ascertain the and uniqueness of this graphic work of art, which we consider the best Spanish on the language of flowers.

KeYwords: Language of flowers, antique illustrations, woman-flower, XIX and XX centuries, Art Nouveau.

Recibido: 06.05.2020. Aceptado: 26.07.2021.

\section{INTRODUCCIÓN}

$\mathrm{E}$ L CROMO, CUYO NOMBRE deriva de la palabra cromolitografía, es uno de los resultados de la revolución técnica de las artes gráficas de mediados del siglo XIX. Es una innovación que consiste en litografiar con varios colores obtenidos por impresiones sucesivas, lo cual permitió la reproducción seriada de colecciones de estampas, vinculadas al consumismo, ya que los cromos se regalaban una vez adquirido un determinado producto. Desde un punto de vista histórico artístico, los cromos antiguos son piezas de las artes gráficas que nos aportan no solo una estética e iconografía en diferentes estilos artísticos, sino que su dimensión se amplía a componentes literarios, sociológicos o de amplias áreas del conocimiento, según su temática.

El presente artículo constituye una investigación inédita sobre una exitosa colección de cromos. Nuestro objeto de estudio se titula El emblema de las flores, y está formado por 100 estampas. La colección corresponde a los primeros años del siglo XX y por los datos obtenidos apuntamos la fecha orientativa de 1910. Fueron distribuidos por la marca de Chocolate Jaume Boix de Barcelona. Cada unidad se regalaba a sus clientes con una tableta de chocolate. La temática en la que se engloba esta colección es lo que podemos entender como "el lenguaje de las flores", un medio de comunicación que estuvo en boga desde el Romanticismo hasta principios del siglo XX. Fue un lenguaje muy arraigado en el ámbito femenino, lo cual nos remite a comportamientos sociales y de género. La extensión y cualidades artísticas y literarias de estos cromos la convierten en la mejor colección española sobre el lenguaje de las flores.

La primera problemática nos la señaló el estado de la cuestión. Eliseu Trenc (1977, pp. 195-196) en su investigación sobre las artes gráficas de la 
época modernista en Barcelona, anotó que se trata de una de las dos únicas colecciones de cromos influidas por la estética modernista ${ }^{1}$. Por su parte, el coleccionista de cromos antiguos Juan Ral (1986 y 2007) incorporó la colección en sus publicaciones. La tercera y última referencia constatada se encuentra en el acervo de la Biblioteca Nacional de España en la que se conserva un ejemplar de la colección (Ramos, 2003, p. 304), aunque con algunas notables particularidades que trataremos más adelante. Las tres fuentes hacen referencia o alguna observación descriptiva a la colección, pero no incluyen comentarios analíticos sobre su contenido.

Nuestro estudio se sitúa cronológicamente entre el siglo XIX e inicios del XX, abarcamos desde el Romanticismo al Art Nouveau. Los resultados de la investigación se han estructurado en dos partes con sus correspondientes metodologías. En primer lugar, efectuamos el análisis formal e iconográfico de esta colección de cromos, comparándola con otras coetáneas de igual tipología y observando en qué radica su singularidad. Con la finalidad de argumentar a favor de la afirmación de Trenc (1977), establecemos relaciones estilísticas con el Art Nouveau. En segundo lugar, realizamos un estudio sobre el tema representado, es decir, el lenguaje de las flores. Para el contenido escrito de estas estampas hemos efectuado una búsqueda de la fuente en la que están basadas, identificada con el libro El lenguaje de las flores y el de las frutas con algunos emblemas de las piedras y los colores. Esta publicación pertenece a la literatura del lenguaje de las flores que trataremos más adelante. Paralelamente, hemos realizado un estudio sobre el citado libro, aportando datos sobre su origen, que ya podemos situar en Latinoamérica. Este hallazgo nos genera otra problemática sobre la difusión desde Latinoamérica a Europa del lenguaje floral, desde el libro hasta la colección de cromos. Con el propósito de ofrecer novedades al respecto, rastreamos las ubicaciones geográficas en América y Europa de donde se editó el libro, en especial las publicaciones en Barcelona donde surgió la colección de cromos. El siguiente paso es ofrecer los resultados de la comparación entre el contenido del libro y los cromos, efectuando un análisis de confrontación del contenido escrito.

El presente texto pertenece a una línea de investigación que venimos desarrollando sobre el lenguaje simbólico de las flores y su relación con la

\footnotetext{
1 "Modernismo" es el término con el que se conoce en España el movimiento Art Nouveau, por lo tanto, los dos vocablos actúan como sinónimos y así los utilizamos en el presente artículo. Este movimiento artístico y cultural internacional, situado cronológicamente entre finales del siglo XIX e inicios del siglo XX, surgió en Inglaterra, Bélgica y Francia, se extendió rápidamente por el resto de Europa y después por América.
} 
representación artística. La historiografía histórico-artística española no ha mostrado un especial interés por el lenguaje de las flores. Presentamos un estado de la cuestión en una anterior publicación (López, 2014, pp. 134135), lo cual justifica la escasa bibliografía, a diferencia de Inglaterra y Estados Unidos (Goody, 1993; Seaton, 1995) que cuenta con investigaciones sobre la materia.

Nuestro objetivo es aportar conocimiento sobre la relación entre el lenguaje floral y los cromos antiguos, un tema de componente simbólico otorgado a los vegetales y una manifestación de las artes gráficas que pretendemos contribuir a dignificar dentro de la investigación histórico-artística. Es nuestro interés poner de manifiesto su importancia como testimonio literario y artístico que refleja las conexiones e intereses comunes entre Latinoamérica y Europa durante los siglos XIX y XX.

\section{EL CROMO, ARTE GRÁFICO REVOLUCIONARIO}

Con el objetivo de plantear un marco introductorio, apuntamos algunas consideraciones sobre el cromo. El proceso cromolitográfico fue inventado en Europa, el año 1837, por Godefroye Engelmann y supuso una auténtica revolución dentro de las artes gráficas, ya que permitió obtener la mejor calidad cromática del momento. A diferencia del continente europeo, en el caso de Latinoamérica, a lo largo del siglo XIX proliferó la litografía, pues se iniciaron en 1826 los talleres de esta técnica (Pas, 2011, p. 14).

El contexto histórico en el que se acogen los cromos del siglo XIX es la revolución industrial con la consecuente proliferación de fábricas y el auge de la economía. De la competencia derivada del aumento de las empresas surgió la necesidad de diferenciación, para ello la publicidad se convirtió en la mejor aliada. El cromo apareció como medio de promoción de productos y las colecciones de estampas contribuyeron a la fidelidad a la marca por parte del consumidor. Los orígenes de la distribución de cromos se remontan a París; se repartieron en los almacenes Au Bon Marché, rápidamente obtuvieron una gran difusión (López, 2013a, pp. 87-89). Los cromos actúan como documentos de carácter sociológico para el estudio de la cultura. Su forma, contenido y medidas son aspectos de su fisonomía relacionados con la publicidad y el coleccionismo (Conde, 1998).

Centrándonos en el caso de Barcelona, donde surgió la colección que tratamos, Trenc (1977, pp. 195-196) fue el primer historiador que otorgó a los cromos la categoría artística dentro de las artes gráficas modernis- 
tas. Posteriormente, han ido apareciendo algunas investigaciones de interés dentro de la historia del arte (Bergadà y Vélez, 1998; Castillo, 1997; Fontbona, 1988). Xavier Soler (2004, pp. 180-182) estudió el grabado popular modernista, dedicando un apartado al cromo Art Nouveau desde una visión general y de conjunto. Es interesante la afirmación en la que señala que el momento culminante del cromo fue la última década del siglo XIX. Sobre la cronología del cromo es destacable la tesis doctoral sobre el cromo victoriano, de García (2015), quien estableció una periodicidad cronológica de los cromos en la época victoriana que comprende cuatro etapas entre 1800 y 1920.

Fue la vertiente del coleccionista y aficionado la que aportó más fuentes en la historia del cromo. Debe hacerse mención especial a Juan Ral (Barcelona, 1922-2010)2 , quien consiguió recopilar alrededor de 1.900 colecciones de cromos antiguos en su dedicación de más de 50 años. La colección Ral se convirtió en una de las más extensas y mejores colecciones de cromos antiguos en España, y permitió establecer el catálogo más completo de cromos antiguos, aquellos que su propietario dividió en dos períodos. El primero va desde finales del siglo XIX hasta 1922, con las guerras de África, y el segundo comprende entre 1922 y 1936, con el inicio de la Guerra Civil española (Ral, 1986 y 2007). Con un planteamiento similar, se crearon títulos de las colecciones que se definían en consenso con otros coleccionistas. Cada colección incluye datos que podríamos considerar registrales, al incorporar título, lugar de publicación y extensión, pero queda pendiente la realización de estudios individuales o grupales. A pesar de las valiosas aportaciones realizadas por los autores citados, no se ha conseguido hasta el momento un estudio unificado y completo de los cromos Art Nouveau, que de seguro determinaría el nexo entre este estilo artístico y las artes gráficas de su época.

\section{EL CASO EXCEPCIONAL DE EL EMBLEMA DE LAS FLORES DE CHOCOLATE JAUME BOIX DE BARCELONA (c.1910)}

En este apartado analizamos el objeto de estudio, la colección de cromos El emblema de las flores (véase Figs. 1-2) desde la perspectiva formal e iconográfica. Efectuamos una comparación con otras colecciones de cromos

\footnotetext{
${ }^{2}$ Gracias a la oportunidad de haber llegado a conocer al Sr. Juan Ral Bolet y que nos mostrara su colección, podemos exponer los presentes resultados.
} 
coetáneos de la misma tipología con el objetivo de dejar patente su excepcionalidad y singularidad. Acompañamos la investigación con un análisis estilístico justificativo del movimiento artístico al que pertenecen, el Art Nouveau.
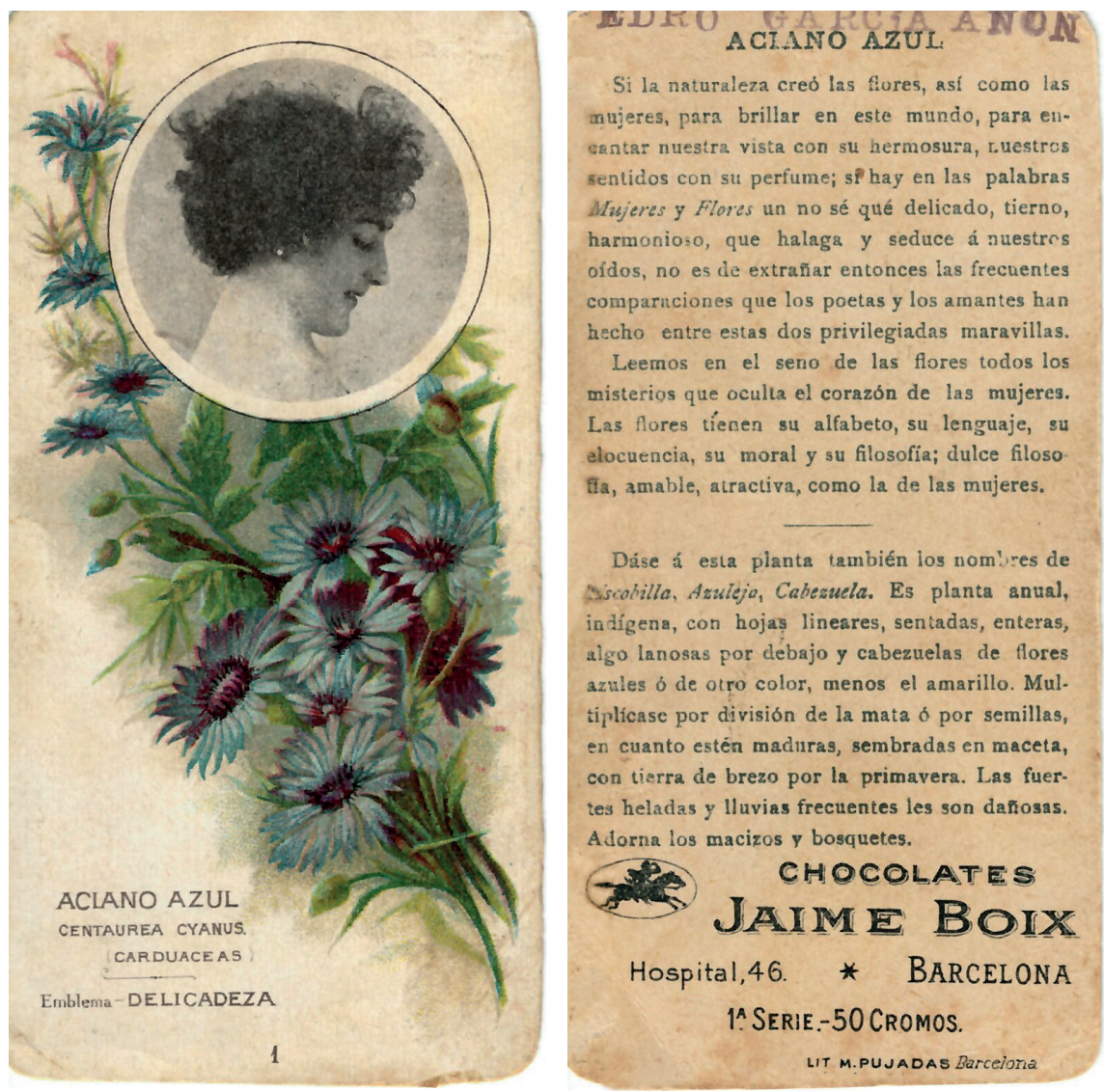

Figuras 1-2. Anverso y reverso del cromo número 1. El emblema de las flores (c. 1910). Colección de la autora.

La colección presenta un formato alargado $(13,5 \times 7 \mathrm{~cm})$, fue impreso por los talleres de litografía M. Pujadas y Thomas de Barcelona con la técnica cromolitográfica con reproducción fotomecánica sobre cartulina. Se hicieron dos series (A y B) de 50 cromos cada una, en total 100 unidades. Hemos podido datar la colección alrededor del año 1910 por el sello del primer coleccionista de nuestra colección particular. Según la periodicidad cronológica de García (2015, pp. 99-101), estos cromos se sitúan en el de- 
clive del cromo victoriano, que comprende del 1900 al 1930.

La colección fue distribuida por la marca de Chocolate Jaume Boix de Barcelona, la que regalaba a sus clientes cromos incorporados en las tabletas de chocolate. La industria chocolatera fue el sector alimenticio que más destacó en la repartición de cromos.

En lo que respecta a la descripción formal, cada uno de los cromos corresponde a una flor, así cada cromo se puede entender como una unidad individualizada que sigue un esquema conjunto en su totalidad. En el anverso se representa un retrato femenino en blanco y negro con la técnica de la reproducción fototipográfica. Cada fotografía acoge un marco en forma geométrica, círculo, cuadrado o rombo. Las imágenes de las mujeres están envueltas por el dibujo de una flor en color. En la parte inferior para la primera serie o la parte superior para la segunda, se indica el nombre de la flor representada; tanto el nombre común como el científico en latín, juntamente con su emblema. En el margen inferior aparece el número al que corresponde el cromo dentro de la colección, como referente orientativo numérico para el consumidor. El reverso se estructura en dos apartados. Los primeros cromos actúan como introducción al lenguaje de las flores y en el resto aparece alguna explicación simbólica de la flor, ya sea una leyenda sobre su origen o un poema. También se incluyen textos que exponen las características de las flores desde el punto de vista de la botánica. El segundo apartado está destinado al estampado del logotipo de la empresa anunciante. Además, se señala si el cromo pertenece a la primera o segunda serie; los de la primera fueron impresos por la litografía M. Pujadas y los de la segunda por la litografía Thomas, ambas de Barcelona.

La colección tuvo que tener buena acogida, puesto que otros anunciantes la imitaron. Tenemos constancia de que una empresa de zapatos española de la época reprodujo 48 cromos, un ejemplar forma parte del fondo de la Biblioteca Nacional de España en Madrid ${ }^{3}$. Es muy similar a la colección del Chocolate Boix, pero consta con el título genérico de El lenguaje de las flores. Es de autor anónimo, sin referencia de editor y datada entre 1900 y 1920 (Ramos, 2003, p. 304). En el anverso la información escrita se ha reducido y por lo tanto es una edición menos cuidada. En el ámbito de la compra-venta del coleccionismo, concretamente en el portal de "todocolección"4 hemos localizado algunos cromos que incluyen el sello de la em-

\footnotetext{
${ }^{3}$ Sede de Recoletos, número de registro EPH/422/1-EPH/422/48, en el fondo reservado de la Sala Goya- Bellas Artes de la Biblioteca Nacional de España.

${ }^{4}$ Portal online de gran repercusión en España, dedicado al mercado de antigüedades, arte, libros y coleccionismo.
} 
presa anunciante Tupinamba, de cafés y productos similares, de Barcelona. La imprenta encargada en este caso fue la litografía M. Pujadas.

En un análisis iconográfico, observamos que generalmente las actitudes de las mujeres representadas no tienen ninguna correspondencia con el emblema floral. Simplemente hemos precisado que cuando se trata de significados religiosos, las mujeres adoptan la posición de rezo, como en los números 73 y 93 . Otra particularidad es que en cada cromo aparece una mujer, excepto en el número 64, donde hay dos, en alusión a la unión, el emblema que representan. Ral (2007, p. 117) afirmó que en 20 cromos de la serie A se hicieron dos tirajes de los rostros femeninos. Esta cuestión nos señala que probablemente se hizo un tiraje considerable que permitió más adelante esta modificación, lo cual reafirmaría su éxito.

Las mujeres representadas en los fotograbados aparecen en algunas ocasiones adornadas con ostentosas joyas. Hemos podido identificar algunas de ellas por el artículo "Joyas y atavíos" (1906) aparecido en la revista Hojas Selectas de Barcelona. Se trata de actrices extranjeras como Cleo de Merode, que es representada en el cromo número 10, además de los 21,73 y 95 , en este último coincide el mismo tocado. La fotografía de la actriz Farraf del artículo (véase Fig. 3) es idéntica a la del cromo número 44 (véase Fig. 4). Esto nos hace pensar que probablemente gran parte de las mujeres que aparecen representadas en los cromos se dedicaban al mundo del espectáculo y que estaríamos ante los inicios de la difusión de la imagen de artistas para las grandes masas.

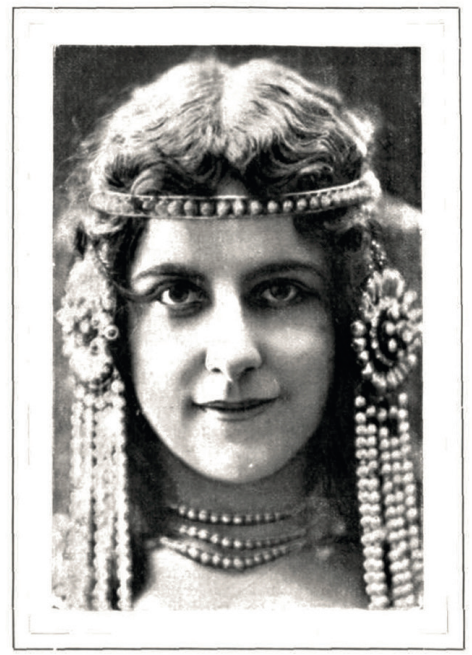

Figura 3. Fotografía de Farraf reproducida en el artículo "Joyas y atavíos" (1906), Hojas Selectas, p. 981. 


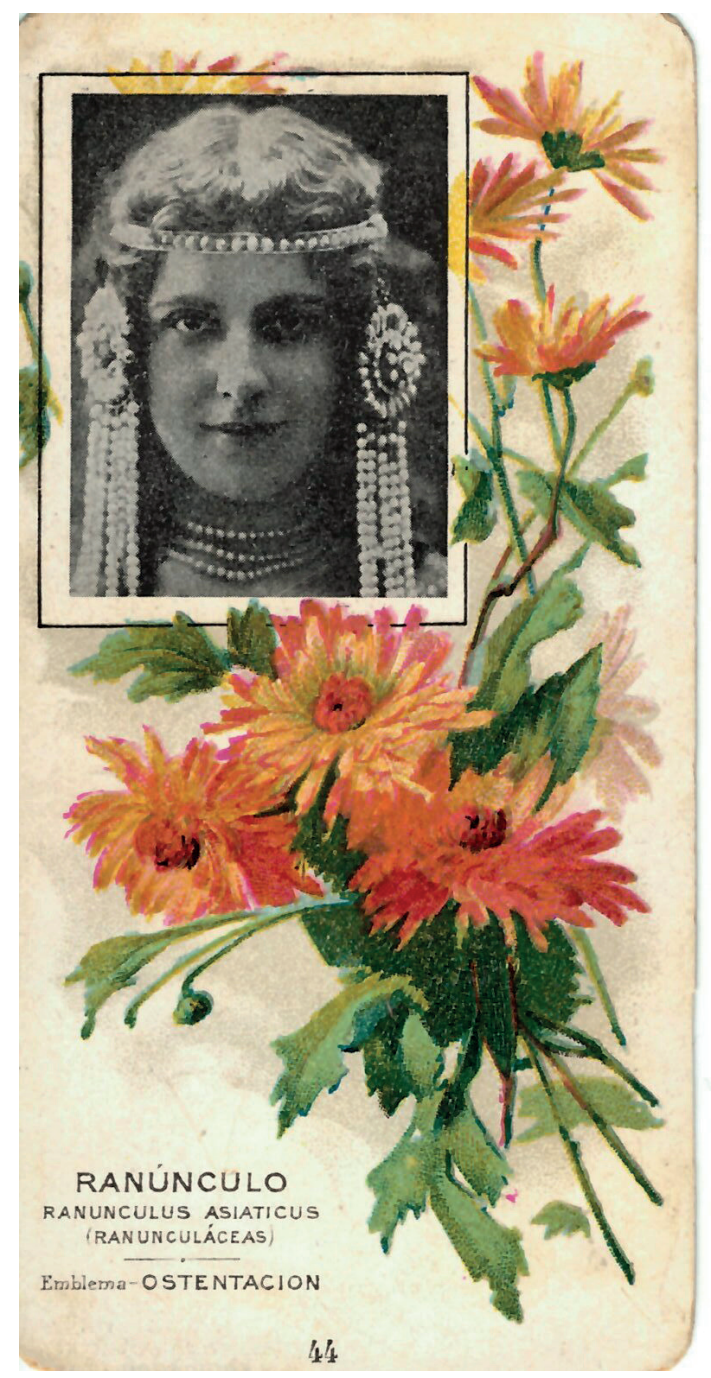

Figura 4. Anverso del cromo número 44 El emblema de las flores (c.1910). Colección de la autora.

Otra observación es que en algunas ocasiones las mujeres llevan en los cabellos la flor representada, como si hubiera una intención de asociación. Así sucede en los crisantemos del número 8, los narcisos del 12, las margaritas del cromo 17 (véase Fig. 5), la forsitia que también está en el vestido del 70 (véase Fig. 6), la flor de azahar en el 97, la adormidera en el 99 y la azucena envuelta en el cuello de la mujer del cromo 41 (véase Fig. 7). 

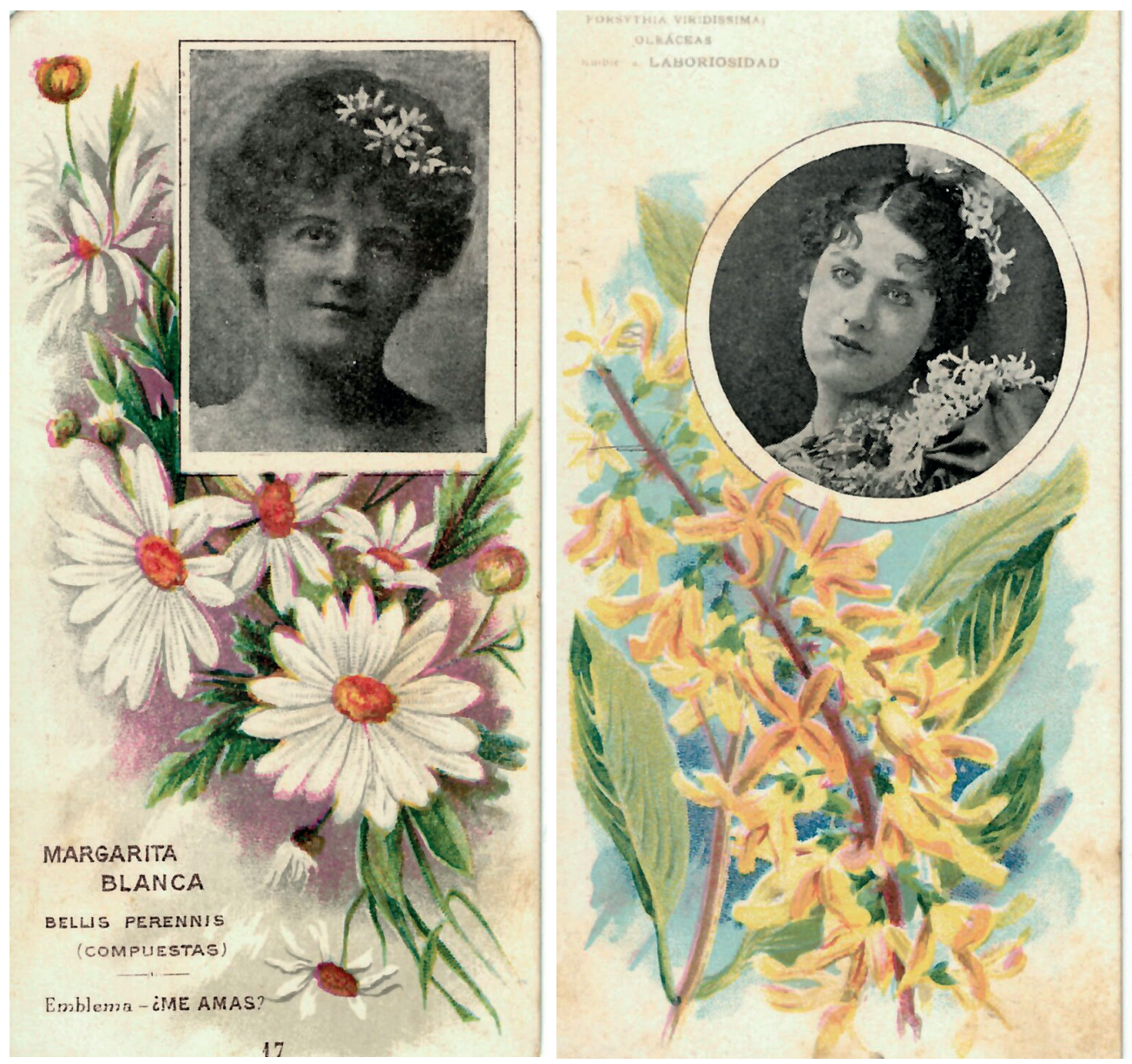

Figuras 5, 6. Anverso de los cromos números 17, 70 El emblema de las flores (c.1910). Colección de la autora. 


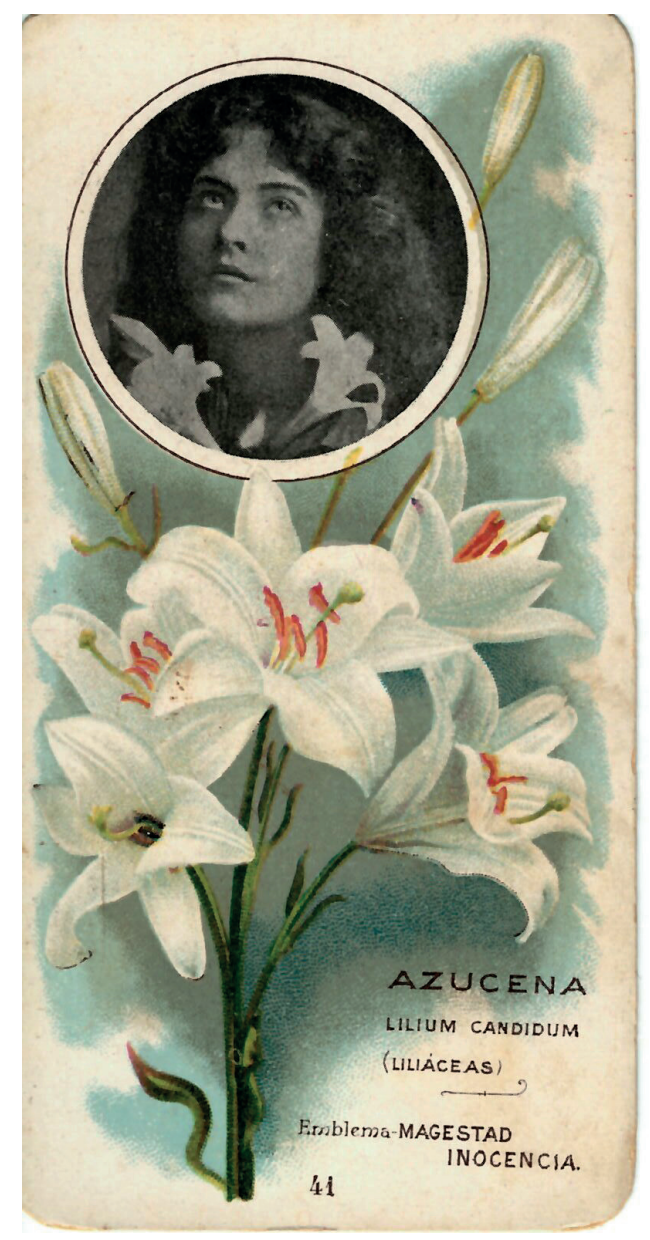

Figura 7. Anverso de los cromos números 41 El emblema de las flores (c.1910). Colección de la autora.

Como indicábamos en líneas anteriores, según Trenc (1977, pp. 195196), El emblema de las flores es una de las dos únicas colecciones de cromos influidas por la estética modernista ${ }^{5}$. La otra corresponde a la colec-

\footnotetext{
${ }^{5} \mathrm{El}$ autor la indica como Las flores y posteriormente Ral la denominó El emblema de las flores. No hay duda de que se trata de la misma colección por las fechas y la ilustración reproducida en el libro de Trenc, que coincide perfectamente con la colección de cromos que tratamos.
} 
ción Astronomía popular, también de la misma marca. Esta afirmación la podemos argumentar a partir del contenido gráfico que relacionamos con el Art Nouveau. Las mujeres y las flores fueron dos temáticas que obtuvieron una destacada relevancia en la iconografía Art Nouveau. Las mujeres representaban el ideal femenino que los artistas identificaban con la Madre Tierra, el símbolo de fertilidad, pero también de abundancia, asociado con el auge consumista de las últimas décadas del siglo XIX (Martí, 2004, p. 127). Por su parte, la ornamentación vegetal fue uno de los repertorios Art Nouveau por excelencia. Este arte nuevo hizo de la naturaleza su fuente de inspiración para alejarse de los historicismos y eclecticismos de décadas precedentes.

Con el fin de contextualizar la colección El emblema de las flores, tratamos algunos cromos que se crearon en el paso del siglo XIX al XX sobre la relación de las mujeres con las flores. Forman parte Bellezas y flores de Lencería Bonet y Reus ( 25 cromos), Señoras y flores del Chocolate Forment (6 cromos) y Mujeres modernistas del Chocolate Amatller ( 25 cromos). En estas estampas la inclusión de las flores responde a una función decorativa y no simbólica, como sucede en los cromos victorianos (García, 2015, p. 281). En relación a los cromos dedicados al lenguaje de las flores, el contenido simbólico predomina por sobre el decorativo. Solo se ha localizado una colección similar en Barcelona, Las flores y su significado (15 cromos) del Chocolate Condal. En esta colección las mujeres se representan como personificaciones de flores al aparecer vestidas con formas simuladoras florales. Nos recuerda el estilo del libro Les fleurs animées publicado en París en 1847, ilustrado por Grandville (López, 2013b). Esta colección presenta una similitud con los cromos editados por el Chocolate Louit Frères \& Cia de Burdeos en Francia (veáse Fig. 8). También se representan mujeres-flor, se indica el nombre de la flor y su emblema. Además, el conjunto decorativo se unifica con el marco superior del cromo que se adorna con la flor correspondiente. 


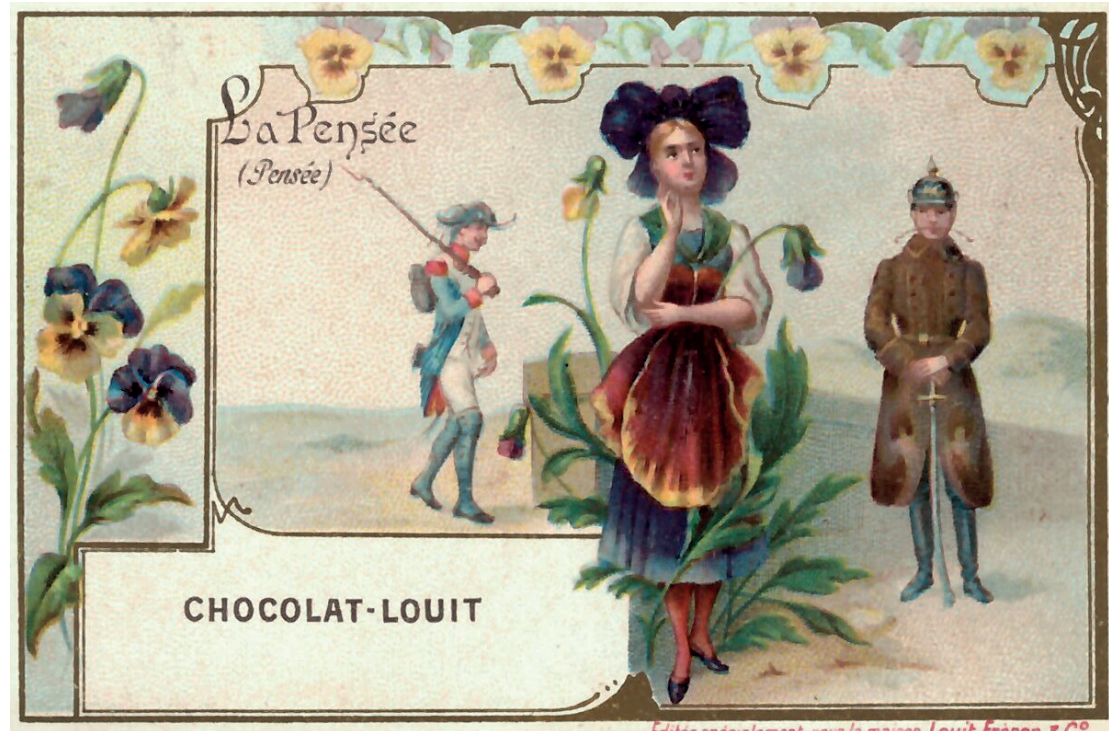

Figura 8. Cromo del Chocolate Louit Frères \& Cia de Burdeos (finales siglo XIX y principios siglo XX). Colección de la autora.

En Madrid se distribuyó El lenguaje de las flores de Almidón Marca El León (15 cromos). En este caso la representación femenina desaparece y el protagonismo es adquirido por la flor que ocupa todo el anverso, se indica el nombre de la flor y su emblema. Las colecciones Las flores y su significado y El lenguaje de las flores están compuestas por un número de cromos considerablemente inferior que el de El emblema de las flores. Se trata de ediciones en las que el contenido escrito es mínimo y hay una diferencia iconográfica en los elementos representados.

En el análisis estilístico de El emblema de las flores, hemos podido observar que las fotografías de las mujeres corresponden a la época, por la estética Art Nouveau. También las ilustraciones de las flores son del estilo Art Nouveau por la representación naturalista que muestran. Por lo que se refiere a la autoría, desconocemos el autor, ya que no aparece ninguna firma y el estilo no nos permite identificarlo con un artista determinado. A pesar del anonimato, la uniformidad de las ilustraciones nos hace inclinarnos por un único artista; sea como fuera, detrás de la elaboración de esta obra 
queda evidente la calidad de la ejecución. Cada flor está trabajada individualmente con variedad de formas y colores, se ajusta al marco del propio formato del cromo y alrededor de las fotografías. Las flores representadas en los cromos victorianos podrían ser utilizadas como herramienta científica ilustrada por la precisión y realidad con la que están trabajadas (García, 2015, pp. 279-280). Es más que probable que el artífice haya utilizado libros o repertorios de botánica como modelo o fuente de inspiración. La complejidad del trabajo hace pensar en la dirección de la figura del anónimo editor del taller litográfico.

\section{EL LENGUAJE ROMÁNTICO DE LAS FLORES: CÓDIGO DE COMUNICACIÓN SECRETO}

Una literatura específica del lenguaje de las flores comienza a editarse en el Romanticismo a inicios del siglo XIX y prolifera hasta inicios del XX. Si bien los orígenes del carácter simbólico de las flores se remiten a la antigua China y Egipto (Seaton, 1995, pp. 42-49), la creación del lenguaje vegetal se asocia a la leyenda oriental del Sélam, tal y como recogieron los primeros lenguajes de las flores franceses (La Tour, c.1850, pp. 3-5; Neuville, 1863, pp. 3-10). Esta leyenda, de un claro carácter amoroso, relata cómo una pareja de enamorados, ante la oposición del padre de ella a que mantuvieran una relación, se fue comunicando a partir del lenguaje simbólico de las flores. Se trata de la codificación de mensajes a través de la flora y su posterior utilización como medio de comunicación por las odaliscas islámicas. La difusión a Occidente se produjo en el siglo XVIII gracias a Lady Wortley, etnóloga británica aficionada, que al visitar Estambul acompañando a su marido, embajador británico en Turquía, pudo observar este lenguaje que dejó recogido en su obra Turkish Embassy Letters, escrita entre 1716-1718 y publicada en 1763. Lady Wortley le describió el peculiar lenguaje a una amiga de la siguiente manera:

No hay color, ni flor, ni mala hierba, ni fruta, ni hierba, ni guijarros, ni plumas, que no tenga un verso que le pertenezca; y puedes pelearte, reprochar, o enviar cartas de pasión, amistad, o cortesía, o incluso de noticias, sin tener nunca los dedos entintados. (Montagu, 1993, p. 116)

\footnotetext{
${ }^{6}$ Traducción de la autora a partir del texto original: "There is no colour, no flower, no weed, no fruit, herb, pebble, or feather, that has not a verse belonging to it; and you may quarrel, reproach, or send letters of passion, friendship, or civility, or even of news, without ever inking your fingers".
} 
El movimiento cultural y artístico del Romanticismo tuvo predilección por lo exótico, de aquí su interés por la cultura oriental, además de lo imaginario e irracional, lo cual propició una difusión de la temática sobre el lenguaje de las flores. En el mismo sentido, durante este periodo el interés por la botánica y la horticultura fue en aumento, asociado a la educación y el disfrute del ocio de las clases privilegiadas (Goody, 1993, pp. 232-241).

La literatura del lenguaje de las flores estaba dirigida básicamente a un público femenino. Es un conjunto de producciones literarias que tienen unos rasgos comunes de contenido narrativo y argumentativo con connotaciones simbólicas. Son libros de medidas reducidas, encuadernaciones sencillas y los más elaborados incluyen algunas ilustraciones de vegetales. Se componen de diccionarios en los que a cada flor se le asigna un sentimiento. Generalmente incluyen el origen de los significados de las flores y las plantas, extraído de la mitología grecolatina y la religión cristiana. A partir del simbolismo de las flores se formula la gramática floral. Esta se efectúa aplicando una estructura de sintaxis, en la cual las flores y las hojas adquieren los atributos de sustantivos y adjetivos con diferentes tiempos verbales. Propiamente, es como si fuese un idioma con toda una serie de normas gramaticales, lo cual denota una gran complejidad (López, 2014, pp. 135-137).

\section{EL LENGUAJE DE LAS FLORES DESDE LATINOAMÉRICA HASTA EUROPA}

En el análisis del contenido escrito de la colección de cromos El emblema de las flores, hemos identificado la fuente de la que se extrae la información escrita, El lenguaje de las flores y el de las frutas con algunos emblemas de las piedras y los colores. De toda la literatura sobre el simbolismo vegetal de los siglos XIX y XX, merece una atención especial este libro. A pesar del gran éxito que consiguió en la época, para la historiografía ha pasado desapercibido, podemos decir que pasó del éxito al olvido. Es de nuestro interés contribuir a su reconocimiento.

La presente investigación nos permite afirmar que el libro fue creado en Caracas por A. Rojas de Rojas Hermanos Editores. El 28 de julio de 1845, el Sr. Mariano Uztáriz, gobernador jefe superior político de Caracas, le concedió a Rojas el derecho exclusivo de publicar y vender la obra que había compuesto y depositado según la ley de 19 de abril de 1839, sobre propiedad de las producciones literarias. Ello le permitió tener la exclusividad de 
publicación y distribución (ver El lenguaje de las flores... 1879, p. 8). Rojas Hermanos Editores realizaron varias ediciones, por ejemplo, se conserva una sexta edición de 1879 en la Biblioteca Nacional de Francia firmada por Florencio Jazmín (ver Jazmín, 1879). Los nombres alusivos al mundo vegetal nos hacen pensar, sin temor a equivocarnos, que se trata de un pseudónimo creado por el propio Rojas. Desde entonces se inició una gran difusión del libro, que fue publicado por otras editoriales, por ejemplo, en el mismo año 1879 se publicó una sexta edición en París y México por la Librería de C. Bouret (ver El lenguaje de las flores... 1879).

Recientemente hemos localizado en la Biblioteca de Letras de la Universidad de Barcelona la primera edición publicada en España. Corresponde a 1857, por la Imprenta de la Sra. Viuda de Saurí é hijo de Barcelona (ver Jazmín, 1857). El hijo, Manuel Saurí, volvió a lanzar la obra en 1870, pero la numeración de ediciones se reinició, pues asignó una primera edición (ver Jazmín, 1870). A la primera edición le siguieron posteriores, ya que ocho años después realizó la segunda (ver Jazmín, 1878) y en 1882 una tercera (ver Jazmín, 1882). En 1894 aparece la cuarta por Saurí y Sabater editores (ver Jazmín, 1894), y ya entrado el siglo XX, la editorial Maucci efectuó un nuevo tiraje; no podemos precisar con seguridad la datación, pero se publicó entre 1913 y 1915 (ver Jazmín, c.1913-1915). Se fueron realizando algunos cambios en relación a la original de Venezuela, pero manteniendo la misma esencia y todas aparecen con el nombre de Jazmín.

Añadimos otro país a la lista, Estados Unidos, con la editorial Appleton y Compañía de Nueva York, con una edición de 1864 (ver El lenguaje de las flores... 1864). Dos años después, la misma editorial vuelve a publicarlo; un ejemplar forma parte del acervo de la Dirección General de Bibliotecas de la Universidad Nacional Autónoma de México (ver Jazmín, 1866). Una década después, en 1876, tenemos constancia de una nueva edición, pues un ejemplar forma parte del fondo bibliotecario del Colegio Nacional de Buenos Aires en la República Argentina (ver Jazmín, 1876).

En un análisis formal del libro, podemos afirmar que en las últimas ediciones publicadas en Barcelona, se llega a componer de un volumen de más de 200 páginas que recoge capítulos de varios autores latinoamericanos, españoles y franceses, ilustrado con láminas de flores a color. Se trata de la vinculación entre niñas, mujeres y flores, historias y poemas sobre las plantas, listados de sus significados y normas de gramática floral. También aparece el calendario floral en el que a cada hora, día de la semana y mes se le asigna una flor. 
Si rastreamos la diversidad de países en los que se publicó el libro, constatamos que primero se publicó en Venezuela, y luego llegó a México, Estados Unidos, Francia y España. Además, se conservan ejemplares de este libro en América y Europa. Esto nos permite constatar el éxito y la difusión internacional que llegó a adquirir en el más de medio siglo de ediciones.

\section{LA RELACIÓN DE LOS CROMOS CON EL LIBRO DEL LENGUAJE DE LAS FLORES}

La correspondencia del libro con los cromos quedaría justificada porque esta publicación procedente de Latinoamérica fue la que obtuvo mayor repercusión en Barcelona sobre el lenguaje floral.

En las tres primeras estampas se realiza una introducción al lenguaje de las flores y su relación con las mujeres, estos textos corresponden al apartado "Introducción" que a su vez son fragmentos traducidos de la obra francesa Rose a douze feuilles. Femmes \& fleurs. Petites photographies badines de Charles Malo (1815) (López, 2013c, p. 319). Observamos que a partir del cromo número 4 , los textos ya se dedican a explicaciones sobre la flor representada. Constatamos que se han extraído algunos fragmentos del apartado "Diccionario del lenguaje de las flores con el origen de sus significados", capítulo en el cual se explican las leyendas sobre la creación de las flores. A su vez, la mayoría de estos textos son traducciones del célebre libro publicado en Francia, Le Langage des fleurs de Charlotte de La Tour (c. 1850), pseudónimo de Louise Cortambert.

Al establecer una comparación de las flores aparecidas en los cromos con el apartado "Catálogo de las flores y hojas de jardín y silvestres con sus significados", listado en el que a cada flor se le asocia un emblema, se observa una clara equivalencia mayoritaria. Aunque hay que precisar que algunas flores no tienen ninguna relación con el libro. Entre estas el crisantemo y el nenúfar; la primera, una flor de moda en la época y la segunda una de las más destacadas del Art Nouveau. Una posible hipótesis que lo justifique es que en la colección de cromos de comienzos del siglo XX se introdujeron nuevas variedades que eran de interés en la época en comparación a las aparecidas en el momento de la publicación del libro.

\footnotetext{
${ }^{7}$ La edición escogida para el análisis comparativo es la de Barcelona de 1894, porque se ajusta mejor a la cronología (ver Jazmín, 1894).
} 


\section{CONCLUSIONES}

La colección de cromos El emblema de las flores combina un lenguaje en boga desde el Romanticismo con una producción técnica y estética del Art Nouveau. Soler (2004, p. 180) afirmó que el Modernismo influyó poco en el mundo del cromo y uno de sus elementos identificadores es el de los recargados marcos. Nuestra colección no recurre al marco, sino a otros elementos estéticos e iconográficos. Por la cronología se ubicaría en un periodo de declive, pero su calidad artística radica en diferentes aspectos alusivos a modernidad, excepcionalidad y singularidad. En primer lugar, desde un punto de vista técnico, es una obra del arte gráfico moderno para su tiempo, al unir la ilustración con la fotografía, aspectos distintivos en relación a otras colecciones del mismo tema o afines. Por los datos obtenidos, nos inclinamos a que el Chocolate Jaume Boix fue el primero en distribuir la colección completa. El éxito y singularidad hizo que aparecieran otras empresas que continuaran de forma parcial y con algunos cambios. La exclusividad en cromos seriados no pertenecería a la empresa anunciante, sino a los talleres litográficos impresores.

Desde la vertiente literaria se produce una adaptación moderna de una obra romántica reeditada El lenguaje de las flores y el de las frutas con algunos emblemas de las piedras y los colores. Originaria de Latinoamérica, se divulgó en Europa, resultando un claro testimonio de la dimensión de su repercusión, que unió a los continentes en un interés común. Del libro a los cromos se produce un nuevo formato, de la literatura romántica a la adaptación sintetizada como mecanismo de la publicidad moderna.

Sobre la función comercial, los pocos casos de cromos alusivos al lenguaje de las flores nos direccionan a considerar que el interés sobre el Emblema de las flores fue mayor por la poca competencia que tuvo. Boix encontró su hueco en el mercado, su distinción ante la competencia. Hay que constatar que estamos ante los inicios de las estrategias de marketing de consumo y el esbozo de la cultura de masas, un concepto innovador en aquella época, en que se potencia la imagen como elemento visual.

En lo que respecta a un punto de vista sociológico, el perfil receptor predominante respondería a un público femenino, el de mujeres cultas, lectoras de esta literatura del lenguaje de las flores, con la inclusión de temas relacionados con la cultura grecolatina, la religión cristiana y la botánica como medio de difusión científico. El perfil descrito alude a un público burgués, consumidor de chocolate, un alimento apreciado en la época y no accesible para todos, con lo cual también se nos permite entender la 
colección como el reflejo de una sociedad, de un imaginario colectivo, en los orígenes del coleccionismo de cromos por parte de las mujeres y, por lo tanto, de la industria cultural relacionada con el ocio burgués a inicios del siglo XX.

Consideramos que la investigación fusiona diferentes disciplinas que integran el simbolismo de la naturaleza, la literatura, el lenguaje romántico con connotaciones de género, las artes gráficas y el fenómeno del coleccionismo burgués. Por lo tanto, quedan planteadas diferentes perspectivas interdisciplinarias desde un análisis crítico histórico, artístico, literario y sociológico.

\section{REFERENCIAS}

Bergadà, E. y Vélez, P. (1998). El Cromo a Catalunya: 1890-1936. Molins de Rei, España: Ayuntamiento de Molins de Rei.

Castillo, M. (1997). Cromos. Grans il.lustradors catalans del llibre per a infants (1905-1939) (pp. 15-16). Barcelona: Barcanova. Biblioteca de Catalunya.

Conde, J. (1998). Lo tengo no lo tengo. Los cromos: historia de una ilusión. Madrid: Espasa.

Fontbona, F. (1988). El cromo, un gènere genuí de les acaballes del segle XIX. Serra d'Or, 349, 67-74.

García, M. (2015). El cromo victoriano como medio de comunicación de masas (1800-1920). Tesis doctoral dirigida por los Drs. Ana Julia Gómez y Javier Ruiz. Málaga: Universidad de Málaga. Documento en línea disponible en http://hdl.handle.net/10630/11635

Goody, J. (1993). The Culture of Flowers. Cambridge; New York: Cambridge University Press.

Jazmín, F. (1857). El lenguaje de las flores y el de las frutas con algunos emblemas de las piedras y los colores. Barcelona: Imprenta de la Sra. Viuda de Saurí é hijo.

Jazmín, F. (1866). El lenguaje de las flores y el de las frutas con algunos emblemas de las piedras y los colores (c. $3^{\mathrm{a}}$ edic.). Nueva York: Appleton y Compañía.

Jazmín, F. (1870). El lenguaje de las flores y el de las frutas con algunos emblemas de las piedras y los colores. Barcelona: Manuel Saurí.

Jazmín, F. (1876). El Lenguaje de las flores y el de las frutas (c. $4^{\text {a }}$ edic.). Nueva York: D. Appleton.

Jazmín, F. (1878). El lenguaje de las flores y el de las frutas con algunos emblemas de las piedras y los colores ( $2^{\text {a }}$ edic.). Barcelona: Manuel Saurí.

Jazmín, F. (1879). El lenguaje de las flores y el de las frutas con algunos emblemas de las piedras y los colores ( 6 a edic.). Caracas, Venezuela: Rojas Hermanos editores. 
Jazmín, F. (1882). El lenguaje de las flores y el de las frutas con algunos emblemas de las piedras y los colores. Edición aumentada con varias poesías alusivas á las flores, El lenguaje del pañuelo y el del abanico adornado con diez magníficos cromos ( $3^{\mathrm{a}}$ edic.). Barcelona: Manuel Saurí.

Jazmín, F. (1894). El lenguaje de las flores y el de los colores adicionado con el de la sombrilla y pañuelo, emblemas de las flores y colores. El valor real que tienen los ojos negros y los azules. Edición aumentada con varias poesías alusivas á las flores. Diez magníficos cromos (4a edic.). Barcelona: Saurí y Sabater Editores.

Jazmín, F. (c. 1913-1915). El lenguaje de las flores y el de los colores: adicionado con el de la sombrilla y pañuelo: emblemas de las flores y colores: valor real que tienen los ojos negros y los azules (5 edic.). Barcelona: Maucci.

Joyas y atavíos. (1906). Hojas Selectas (s.n), 977-986. Documento en línea disponible en http://hemerotecadigital.bne.es/details.vm?q=id:0001327755\& lang=es,

La Tour, Ch. (c. 1850). Le Langage des fleurs (8 ${ }^{\mathrm{a}}$ edic.). Paris: Garnier Frères.

El lenguaje de las flores y el de las frutas con algunos emblemas de las piedras y los colores (1864) (c. $2^{\text {a }}$ edic.). Nueva York: Appleton y Compañía.

El lenguaje de las flores y el de las frutas con algunos emblemas de las piedras y los colores (1879) (6 $6^{\mathrm{a}}$ edic.). París-Ciudad de México: Librería de C. Bouret.

López, F. (2013a). Picture card collecting En T.-M. Sala (coord.). Considering and interpreting leisure. Pastimes, entertainments, hobbies and addictions in the Barcelona of 1900 (pp. 87-101). Barcelona: Publicaciones y Ediciones Universidad de Barcelona. Colección Singularidades. Documento en línea disponible en http://www.publicacions.ub.edu/ficha.aspx? cod=07727

López, F. (2013b). Les fleurs animées (1847): la fusió simbòlica de la dona-flor. Emblecat, 2, 127-136. Artículo en línea disponible en https://www.raco.cat/ index.php/EMBLECAT/article/view/304799/0

López, F. (2013c). El lenguaje de las flores en el Modernismo de Barcelona: precedentes e influencias francesas. En A. Martínez, I. Osuna, y V. Infantes (eds.). Palabras, símbolos, emblemas. Las estructuras gráficas de la representación (pp. 313-321). Madrid: Turpin Editores. Sociedad Española de Emblemática. Documento en línea disponible en http://emblematica.es/ anejo-2

López, F. (2014). Las mujeres y el lenguaje de las flores en la Barcelona de los siglos XIX y XX. Temas de Mujeres. Revista del CEHIM Centro de Estudios Históricos e Interdisciplinarios sobre las Mujeres, 10, 129-149. Artículo en línea disponible en http://filo.unt.edu.ar/wp-content/uploads/2015/11/TEMAS_MUJERES_010_10-L\%C3\%93PEZ-P\%C3\%89REZ.pdf

Malo, Ch. (1815). Rose a douze feuilles. Femmes \& fleurs. Petites photographies badines ( $2^{\text {a }}$ edic.). Paris: Achille Faure.

Martí, M. A. (2004). El plaer de la xocolata: la història i la cultura de la xocolata a Catalunya. Valls, España: Cossetània.

Montagu, M. W. (1993). Turkish embassy letters. Londres: William Pickering. 
Neuville, A. (1863). Le Véritable langage des fleurs. Précède de légendes mythologiques; illustré de bouquets en couleur et de vignettes par Alp. Guilletat. Paris: Bernardin-Béchet.

Pas, H.F. (2011). La seducción de las imágenes. El ingreso de la litografía y los nuevos modos de publicidad en Latinoamérica. Caracol, 2, 1041. Artículo en línea, disponible en https://dialnet.unirioja.es/servlet/ articulo?codigo $=5215958$

Ral, J. (1986). Catálogo del cromo antiguo en España. Barcelona: Impr. CopiArt.

Ral, J. (2007). Cromos para recordar. Barcelona: Creaciones Graf.32.

Ramos, R. (2003). Ephemera: la vida sobre papel: colección de la Biblioteca Nacional. Madrid: Biblioteca Nacional.

Seaton, B. (1995). Language of flowers. Virginia: The University Press of Virginia.

Soler, X. (2004). El gravat popular. En F. Fontbona (dir.). El Modernisme. Vol. V: En paral.lel al Modernisme (pp. 180-185). Barcelona: Edicions L'Isard.

Trenc, E. (1977). Les arts gràfiques de lèpoca modernista a Barcelona. Barcelona: Gremi d'Indústries de Barcelona. 